\title{
Critérios de conservação regional da zebra das planícies (equus quagga crawshayi) na Reserva Especial do Niassa
}

Nos últimos anos a Reserva Especial do Niassa (REN) enfrenta grandes ameaças relacionadas com a conservação da sua biodiversidade, tais como os incêndios florestais, exploração mineira ilegal, pesca comercial, envenenamento de animais, conflitos homem-fauna bravios e a perda de habitat. $\mathrm{O}$ objetivo deste estudo foi de avaliar os critérios para conservação regional da Zebra das planícies da subespécie Equus quagga crawshayi na Reserva Especial do Niassa, que está localizada a 36025'E de longitude, ocupando uma área de 42.000 Km2 em 1/3 da Província do Niassa e dois distritos de Cabo Delgado. A coleta de dados foi efetuada com o auxílio das metodologias de identificação da fauna com carros, procura dos representantes persistentes e estáticos e a metodologia de armadilhas fotográficas na qual foi recentemente introduzida naquela região. Na análise de dados foi empregue Software computacional de criação de planilhas eletrônicas Microsoft Office Excel 2010 e o programa da ESRI, denominado ArcGIS na sua versão 10.3. A Zebra foi encontrada em 5 das 6 classes de vegetação existentes na REN em busca da vegetação herbácea, água e percorrendo corredores junto com as outras espécies. Os valores da extensão de ocorrência (EOO) (que constitui cerca de $48,96 \%$ da área total) e da área de ocupação (AOO) (cerca de 4,62\% quando comparada com a área da REN) encontrados neste estudo indicam que a população da Zebra enfrenta uma fragmentação severa na sua área de ocupação porque apresenta maior parte dos grupos de indivíduos isolados uns dos outros na sua extensão de ocorrência, mas também por necessitar de condições muito específicas de habitat e por consequente apresentar seus indivíduos em subpopulações pequenas e relativamente isoladas, aumentando o risco de extinção da espécie.

\section{Regional criteria of conservation of plains zebra (equus quagga crawshayi) in the Niassa Special Reserve}

In recent years Niassa special Reserve (NER) faces major threats related to the conservation of biodiversity, such as forest fires, illegal mining, commercial fishing animal poisoning, human-wildlife conflicts and habitat loss. The objective of this study was to evaluate the criteria for regional conservation of Zebra plains of the subspecies Equus quagga crawshayi in the Niassa special Reserve, which is located 36025'E longitude, occupying an area of $42,000 \mathrm{Km} 2$ in $1 / 3$ of the Province of Niassa and two districts of Cabo Delgado Province. The data collection was carried out with the aid of the fauna identification methodologies with cars, search of the persistent and static representatives and the camera traping methodology in which it was recently introduced in that region. In the data analysis was used Computer software to create spreadsheets Microsoft Office Excel 2010 and ESRI program, called ArcGIS in its version 10.3. Zebra was found in 5 of the 6 existing vegetation classes in the NER in search of herbaceous vegetation, water and running along corridors along with other species. The values of occurrence extension (constituting about $48.96 \%$ of the total area) and occupation area (4.62\%) found in this study indicate that the Zebra population faces severe fragmentation in their occupation area because it presents most of the groups of individuals isolated from each other in their extent of occurrence, but also because they require very specific habitat conditions and consequently present their individuals in small and relatively isolated subpopulations, increasing the risk of species extinction.

Keywords: Camera traping; Occupation area; Occurrence extension.

Topic: Conservação da Biodiversidade

Reviewed anonymously in the process of blind peer.

\section{Atanásio Félix (iD}

Instituto de Investigação Agrária de Moçambique, Moçambique http://lattes.cnpq.br/1055838700942347

http://orcid.org/0000-0001-7224-0933

atanasiofelix32@gmail.com

Remigio Rangel Nhamussua (iD

Universidade Lúrio, Moçambique

http://lattes.cnpq.br/3126647336219362

http://orcid.org/0000-0002-1316-8297

remigiox70@yahoo.com.br

Merlindo Jacinto Manjate

Universidade Lúrio, Moçambique

http://lattes.cnpq.br/6067118027738336

http://orcid.org/0000-0001-9574-9687

merlindomanjate@unilurio.ac.mz

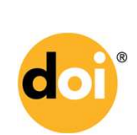

DOI: 10.6008/CBPC2318-2881.2020.004.0002
Received: 08/09/2020

Approved: 02/11/2020

\author{
Arlindo de Fátima Justino Manuel ib \\ Universidade Lúrio, Moçambique \\ http://lattes.cnpq.br/8449770839795422 \\ http://orcid.org/0000-0001-5487-0827 \\ porquenaolindo@gmail.com
}

Referencing this:

FÉLIX, A.; NHAMUSSUA, R. R.; MANJATE, M. J.; MANUEL, A. F. J.. Critérios de conservação regional da zebra das planícies (equus quagga crawshayi) na Reserva Especial do Niassa. Nature and Conservation, v.13, n.4, p.12-21, 2020. DOI:

http://doi.org/10.6008/CBPC2318-2881.2020.004.0002 


\section{INTRODUÇÃO}

Num contexto global, a diversidade faunística é um bem comum essencial para a sobrevivência da humanidade na Terra. Seu valor intrínseco e extrínseco tem sido amplamente reconhecido por Governos e Sociedade Civil em diversos acordos internacionais (PERES et al., 2011).

A população de Zebras em Moçambique não foi descrita como extinta, mas seu número de indivíduos é muito reduzido, o que faz com que haja introdução dessas espécies em algumas áreas de conservação (KING et al., 2016). No ano de 2015, a Reserva Especial de Maputo levou a cabo o processo de repovoamento de 225 animais de diferentes espécies, com destaque para zebras, impalas, cudos e girafas oferecidos pelo governo sul-africano (SELEMANE et al., 2015). Em 2012 foram reintroduzidas 14 zebras das planícies no Parque Nacional da Gorongosa (PNG) (BEGG et al., 2015, citado por KING et al., 2016). No ano 2013, sete zebras foram novamente reintroduzidas no Parque Nacional da Gorongosa, para aumentar o número de indivíduos dessa espécie que ainda é reduzida nessa área. Entre 2002 e 2008, 1361 zebras foram reintroduzidas na secção ocidental do Parque Nacional do Limpopo (PNL), número que sofreu grande redução devido à caça furtiva (EVERATT, 2015).

A Reserva Especial do Niassa (REN) é uma área coberta por grandes extensões de floresta de Miombo, com precipitações anuais que variam entre $1400 \mathrm{~mm}$ ou mais na montanha de Mecula e $600 \mathrm{~mm}$ nos vales dos rios Rovuma e Lugenda. Esta importante área alberga vasta diversidade de fauna bravia com destaque elefantes, leões, búfalos, pala-palas, zebras entre outras espécies. Os incêndios florestais, exploração mineira ilegal, pesca comercial, envenenamento de animais, conflitos homem-fauna bravios e a perda de habitat constituem uma grande ameaça para a fauna bravia dentro da Reserva Especial do Niassa, incluindo a população de zebras. Todas essas ameaças têm impactos sobre a população da Zebra, fazendo com que sejam verificados casos de dados como os que foram publicados por Begg et al. (2015, citado por KING et al., 2016), na qual a Zebra sofreu diminuições no tamanho de sua população desde 2009 a 2014. Segundo este autor, a população da zebra da REN foi estimada em números aproximados a 6.000 para o ano de 2009 e 3.000 para o ano de 2014. A presente pesquisa faz uma avaliação da Zebra das planícies na REN (com as técnicas recomendadas pela UICN) utilizando critérios que detectam sintomas de ameaça da espécie, de modo que possam ser aplicadas as medidas de contenção de qualquer processo que resulte em consequências como declínio populacional, deriva genética e eventos estocásticos.

\section{METODOLOGIA}

\section{Área de estudo}

A ANAC (2015) refere que a Reserva Especial do Niassa está localizada a $36^{\circ} 25^{\prime} E$ de longitude e faz mais de $30 \mathrm{~km}$ de fronteira com a Tanzânia a Norte. Possui uma superfície total de $42000 \mathrm{Km}^{2}$ ocupando cerca de 1/3 da província de Niassa, concretamente os distritos de Mecula (totalmente dentro da REN), Mavago (98\% dentro da REN), parte dos distritos de Muembe, Majune, Marrupa, Sanga e parte dos distritos de Mueda (posto administrativo de Negomano) e Montepuez (Xixano - posto administrativo de Nairoto), na 
Província de Cabo Delgado. A Reserva Especial de Niassa é limitada pelo rio Rovuma a Norte, Rio Lugenda a Sudeste, Rio Luatize a Sudoeste e pelo rio Lussanhando no estremo oeste (Figura 1).

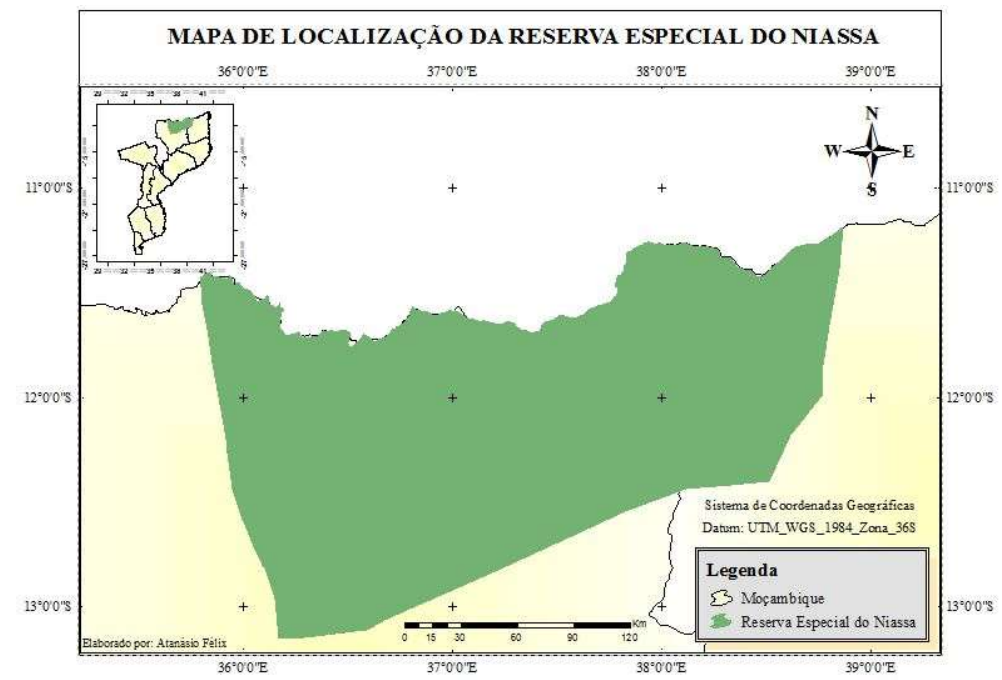

Figura 1: Mapa de localização da Reserva Especial de Niassa.

Segundo a SRN (S/d), a REN possui um clima tropical húmido, com precipitação durante a estação quente novembro-abril. A Precipitação média anual varia de $1400 \mathrm{~mm}$ na montanha de Mecula até $600 \mathrm{~mm}$, nos vales dos rios Rovuma e Lugenda. As temperaturas médias mensais podem atingir $30 \circ \mathrm{C}$ em outubro e novembro, enquanto a média dos meses mais frescos da estação seca (maio - agosto), varia entre 20 $\mathrm{C} \mathrm{e}$ 26ํㅡ. A parte ocidental é constituída por um terreno cortado por elevações, enquanto a parte oriental é menos alta e mais plana. Diversos picos na parte ocidental atingem mais de $1100 \mathrm{~m}$, mas as terras baixas adjacentes à confluência dos rios Rovuma/Lugenda têm uma altura de menos de $100 \mathrm{~m}$. A montanha de Mecula é um inselbergs isolado no centro da Reserva erguendo-se a mais de 1000m acima da planície circundante. As características dos solos variam de areno-argilosos, profundos e permeáveis de pouca fertilidade a solos inférteis de camadas superficiais e finas de areia, frequentemente vulneráveis à erosão.

O rio Rovuma atravessa a REN a Norte e o rio Lugenda a Este. O Sul é compreendido pelos rios Luatise, Luambala, Luchimua, Lureco, Lucheringo, Messinge e Chiulezi. A montanha de Mecula representa uma importante faceta na hidrologia da Reserva, pois, é suficientemente alta para causar chuvas orográficas nas áreas circunvizinhas gerando água que alimenta os rios Ncuti e o Licombe. Os dambos são depressões hidromórficas suaves ou vales extensos não profundos que são encontradas em algumas zonas da REN (SRN, $S / d)$.

Mais de $70 \%$ da área total da Reserva Nacional de Niassa é coberta por floresta de Miombo que inclui mais 800 espécies de plantas, metade das quais endémicas. A vegetação dentro da REN subdivide-se em 6 classes, designadamente, Floresta Aberta Decídua, Floresta Densa Decídua, Floresta Sempre Verde, Dambos (Pradaria inundada), Vegetação Ribeirinha e Floresta com Agricultura Itinerante (CRAIG, 2009; MARZOLI, 2007; RIBEIRO 2005; TIMBERLAKE et al., 2004, citados por CANGELA, 2014).

Segundo a Expert África, até ao ano de 2012 estimava-se que a REN tinha entre 12.000 elefantes, 10.000 palancas-negras, 800 leões e 200 mabecos (em perigo de extinção). Existem também grandes 
populações de búfalos africanos, impalas, gnus, zebras e leopardos. Também existem 8 tipos de mangosta, 24 tipos de carnívoros e 300 a 400 espécies de aves.

Ao longo de décadas foi ocupada por famílias locais que vivem em grupos relativamente isolados e, atualmente conta com cerca de 40.000 habitantes distribuídos em 50 aldeias incluindo duas sedes distritais, nomeadamente, Mecula e Mavago. A densidade populacional é baixa e varia de 0,8 habitantes $/ \mathrm{km}^{2} \mathrm{em}$ Mecula e 1,9 habitantes $/ \mathrm{Km}^{2}$ no distrito de Mavago. Grande parte da população vive dedicando-se à prática de agricultura de subsistência incluindo outras atividades como extração de mel, lenha, caça e comércio de pequena escala e vivem com menos de 60 Meticais por dia. A população que reside na REN realiza o comércio com os restantes distritos da província de Niassa ao mesmo tempo que estabelece laços comerciais com a vizinha Tanzânia. As principais culturas de rendimento são o tabaco e algodão. O fomento pecuário é muito baixo, provavelmente devido à existência de predadores como, por exemplo, leões, leopardos e hienas (CUNLIFFE et al., 2009; MAE, 2005, citados por CANGELA, 2014).

\section{Coleta de dados}

Os dados foram colhidos nos meses de setembro a dezembro de 2017, na qual envolveu a coleta de coordenadas geográficas e avaliação qualitativa dos locais onde a população da Zebra é encontrada na REN. Para tal, metodologias diferentes foram aplicadas, a saber:

Identificação com carros: Os pontos foram identificados considerando que as redes de estradas existentes dentro de cada unidade de gestão constituíam transectos permanentes. A observação foi feita nas duas faixas de rodagem e efetuou-se a paragem nos locais onde foram observados os indivíduos da espécie para a marcação do respetivo ponto.

Procura dos representantes persistentes e estáticos: Os representantes dos animais foram procurados nas coordenadas geográficas obtidas com GPS, dos bebedouros e rotas de herbívoros colhidos por fiscais durante a sua patrulha em diferentes períodos do ano. Pontos foram remarcados em locais onde se verificou a presença de qualquer um dos representantes da espécie. Essa metodologia que, normalmente fornece bons resultados qualitativos foi adoptada para completar os dados obtidos através da identificação com carro, porque que muitos animais são raramente vistos porque aprenderam a evitar o ser humano devido a vários motivos.

Camera traping: A obtenção dos pontos consistiu no uso de câmaras fotográficas equipadas com censores de movimento (Figura 2). Usou-se o desenho amostral do programa de monitoramento de animais do PCN, que é efetuado nas épocas secas do ano (de abril a setembro) e que utiliza Grids de 2x2 km gerados pelo software de sensoriamento remoto $\operatorname{arcGIS}$, na versão 10.3 (Figura 3). Os dados sobre as características do local foram obtidos durante o processo de monitoria das câmaras que é efetuado em intervalos de 10 dias. As coordenadas geográficas da ocorrência da zebra foram obtidas durante a análise das imagens do mês de setembro de 2017.

Essa metodologia usa equipamentos electrónicos amplamente utilizados para fins conservacionistas, em especial para estudos populacionais ou de comunidades de mamíferos terrestres de médio e grande 
porte, por ser um método não invasivo e eficaz no estudo da vida selvagem (CUNHA, 2013). E ainda, é uma ferramenta excecional para inferências científicas sólidas nos inventários faunísticos, estudos de ocupação e na estimativa de densidade populacionais, desde que os estudos sejam devidamente projetados e o sistema de câmara adequado seja usado (ROVERO et al., 2013).

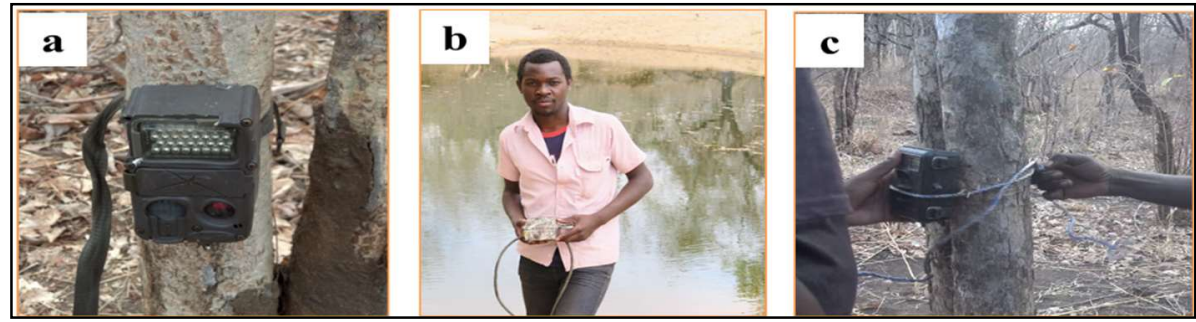

Figura 2: Processo de monitoria das máquinas fotográficas do método Camera traping. Onde: a - máquina fotográfica; b - substituição das pilhas; c - montagem da máquina fotográfica.

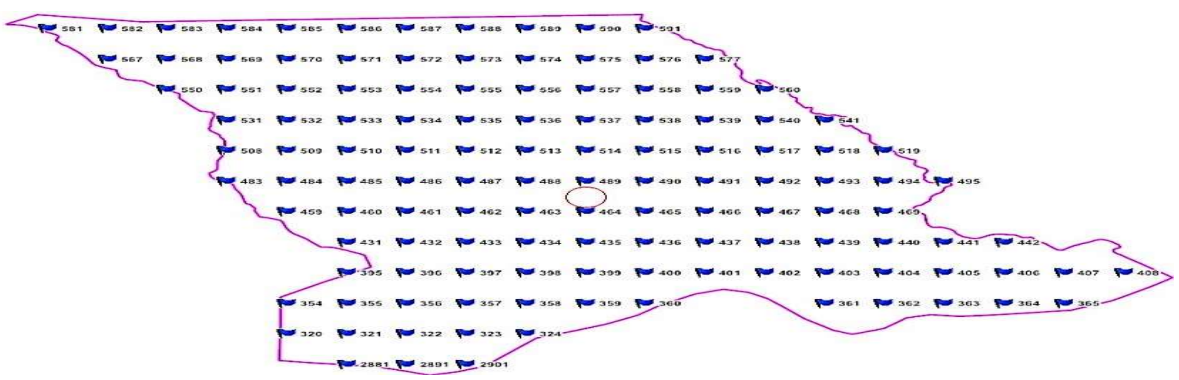

Figura 3: Ilustração da distribuição das máquinas fotográficas em formato de grid no bloco L5S. Fonte: PCN (2017, dados não publicados).

Nesta fase, também foi feito o estudo de campo com ajuda de fiscais e técnicos de conservação, usando a ficha de coleta e caracterização dos locais de ocorrência, para efetuar o levantamento das características do habitat nos locais de ocorrência da zebra. Boni et al. (2005) dizem que esta técnica obriga o pesquisador a ter um contato mais direto com a realidade e é usada para conseguir informações sob determinados aspectos dos quais os indivíduos não têm consciência.

Os dados cartográficos em formato Shapfile (Shp) encontrados na REN foram complementados com outros no mesmo formato, adquiridos na plataforma online do Centro Nacional de Cartografia e Teledeteç̧ão (CENACARTA).

\section{Análise de dados}

$\mathrm{Na}$ análise de dados foi empregue o Software computacional de criação de planilhas eletrônicas Microsoft Office Excel 2010, para organização de dados. O programa da Environmental Systems Research Institute (ESRI) denominado ArcGIS na sua versão 10.3 foi usado para o lançamento e processamento das coordenadas geográficas, locais de ocorrência, extensão de ocorrência (EOO) e área de ocupação (AOO), das quais todas as camadas geradas foram aplicadas ao sistema de projeção de coordenadas geográficas UTM WGS 1984, na zona $36 S$.

A identificação das classes de vegetação de ocorrência de Zebra foi feito com o auxílio de dados cartográficos da REN e para a elaboração do mapa de localização da população, dados de coordenadas geográficas foram organizados e gravados na extensão arquivos binários na planilha de processamento de 
dados do Microsoft Excel 2010 e posteriormente carregados e convertidos em formato Shp no ambiente de processamento de dados do ArcGIS 10.3 pela ferramenta: ArcToolbox - projections and transformations Raster - Convert Coordinate Notation. O shp obtido foi sobreposto com o de localização geográfica da REN para a obtenção do layout final.

De acordo com Moat (2007), para definir o termo local de ocorrência podemos recorrer a definição de botânica para empregar o contexto de uma localidade de coleta, e não à definição de localização, que incorpora a presença ou ausência de um evento ameaçador a sobrevivência da espécie. Consequentemente a este aspecto, as amostras georreferenciadas com as mesmas coordenadas são tratadas como a mesma localidade.

Torna-se importante identificar os locais de ocorrência da espécie porque ajuda no processo de tomada de decisões sobre o maneio direcionado. O MINAM (2015) diz que em uma escala global os mamíferos se encontram entre os vertebrados de maior distribuição geográfica devido a sua adaptabilidade a várias condições geográficas.

A EOO foi obtida com base na vetorização das regras de determinação do Mínimo Polígono Convexo (MPC), com o emprego do shp da localização da população pelo processo de conversão de ponto para linha (ArcToolbox - Data Management Tools - Features - Points To Line) seguindo a conversão para polígono (ArcToolbox - Data Management Tools - Features - Features To Polygon). A área de cada uma das seis (6) camadas formadas foram calculadas por adição de campos nas suas tabelas de atributos (Open Attribute Table - Table Options - Add Field - Calculate Geometry) e posteriormente somadas para obter o resultado final com a unidade de medida dos dados em $\mathrm{km}^{2}$.

Define-se a EOO como sendo a área contida dentro do limite imaginário contínuo mais curto que pode ser desenhado para abranger todos os locais conhecidos, inferidos ou projetados de ocorrência atual de um determinado nível taxionómico, na qual são exclusos os casos de migração ou emigração. Geralmente pode ser medida pela aplicação do MPC, que é o polígono mais pequeno em que nenhum ângulo interno excede 180 e que contém todos os locais de ocorrência (ALA, 2015). Para Moat (2007), o cálculo da EOO pelo método MPC é o mesmo que imaginar uma banda elástica que está sendo puxada sobre todos os pontos. Assim, a EOO será determinada pelo cálculo da área delimitada pela linha e é medida em $\mathrm{km}^{2}$. O autor ainda ressalta que o MPC poderá ser calculado somente se houver pelo menos três pontos de distribuição ou localidades da espécie.

A ALA (2015) define a AOO como sendo a área dentro de EOO que é ocupada por um determinado nível taxionómico, excluindo de migração e emigração, na qual seu tamanho será uma função da escala em que é medida.

A AOO foi determinada pelo método de esquadrinhamento no qual toda a área foi sobreposta a grids com um tamanho constante de $2 \times 2 \mathrm{~km}$ e com tamanho do ponto ajustado na sua respectiva escala e usando o mesmo arquivo shp da localização da população, no qual foi submetido ao seguinte processo: ArcToolbox - Cartography Tools - Data Driven Pages - Grid Index Features. O tamanho de cada área foi encontrado através da multiplicação de grids agrupados com o tamanho do grid, na unidade de média em $\mathrm{km}^{2} \mathrm{e}$ 
posteriormente foi calculada a área total com base na fórmula 3 abaixo apresentada. De acordo com ICMBIO (2013), a AOO será determinada como a área ou a soma das áreas ocupadas pela espécie no interior da sua EOO, dada pela fórmula:

$$
A O O=A_{1}+A_{2}+\ldots+A_{n}
$$

Onde: $A O O$ - área de ocupação $\left(\mathrm{km}^{2}\right) ; A$ - área $\left(\mathrm{km}^{2}\right) ; n$ - número da área.

\section{RESULTADOS}

\section{Localização da população}

A Zebra das planícies foi encontrada em 5 das 6 classes de vegetação existentes na REN, a saber: na Floresta Aberta Decídua, nos Dambos, na Vegetação Ribeirinha, na Floresta Sempre Verde e na Floresta Densa Decídua. A espécie foi encontrada na Floresta Aberta Decídua e nos Dambos em busca da vegetação herbácea (para a sua alimentação) que cresce nessas áreas que possuem pequenos estratos de relevo plano. Na Vegetação Ribeirinha e na Floresta Sempre Verde a espécie foi encontrada em busca da água nos cursos ou charcos que são permanentes durante todo o ano.

Os locais de ocorrência da Zebra das planícies na REN, na qual foram obtidos por coordenadas geográficas são apresentados na figura 4.

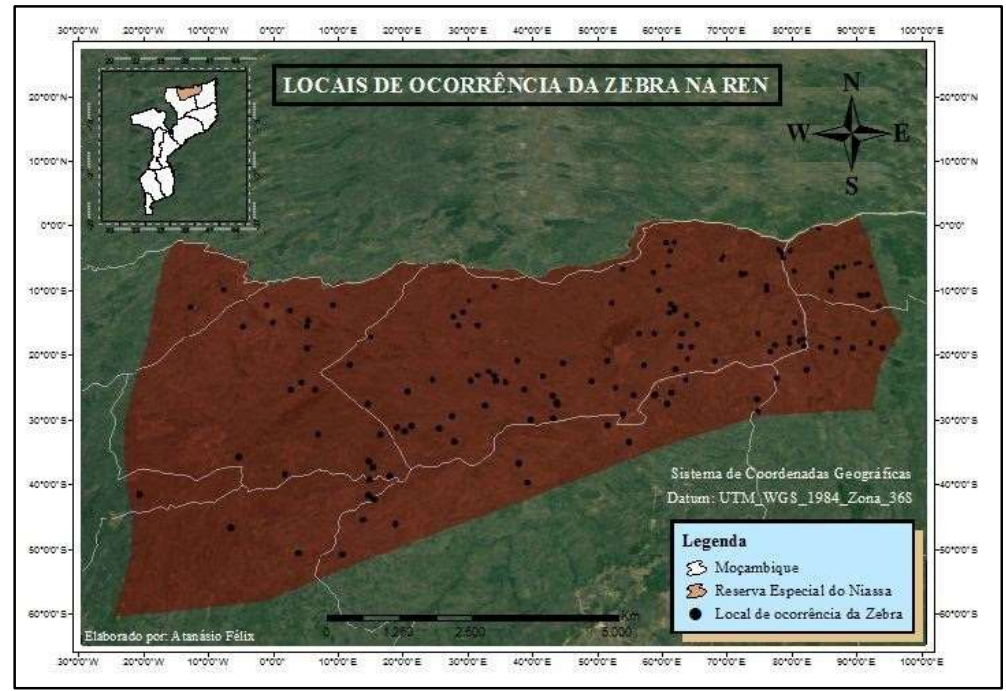

Figura 4: Mapa dos locais de ocorrência da população da Zebra das planícies (Equus quagga crawshayi) na REN no ano de 2017.

\section{Extensão de ocorrência}

A tabela 1 abaixo apresenta os resultados dos MPC's encontrados (em $\mathrm{km}^{2}$ ) e seus respectivos valores percentuais da área ocupada em relação a área total e verifica-se uma EOO da zebra em torno de 48,96\% da área total, indicando que os restantes 51,04\% (na qual se trata de maior parte dessa área) não são explorados pela espécie.

Tabela 1: Valores de cada MPC e a sua respectiva EOO da população da Zebra das planícies (Equus quagga crawshayi) encontrada na REN, no ano de 2017.

\begin{tabular}{l|l|l}
\hline \hline MPC & Área $\left(\mathrm{km}^{2}\right)$ & Área (\%) \\
\hline 1 & 3.145 & 7,49
\end{tabular}




\begin{tabular}{|c|c|c|}
\hline 2 & 7.531 & $17,93$. \\
\hline 3 & 336 & 0,80 \\
\hline 4 & 4.275 & $10,18$. \\
\hline 5 & 3.310 & 7,88 \\
\hline 6 & 1.965 & 4,68 \\
\hline EOO & 20.562 & 48,96 \\
\hline
\end{tabular}

\section{Área de ocupação}

A AOO encontrada foi de $1.940 \mathrm{~km}^{2}$, indicando que numa perspectiva de conservação ex-situ, essa área seria o mínimo necessário com o número de indivíduos encontrados atualmente na REN. Este valor indica cerca de 0,09\% em comparação com a AOO da avaliação global da espécie, que é de $2.250 .000 \mathrm{~km}^{2} \mathrm{e}$ cerca de 4,62\% quando comparada com a área da REN.

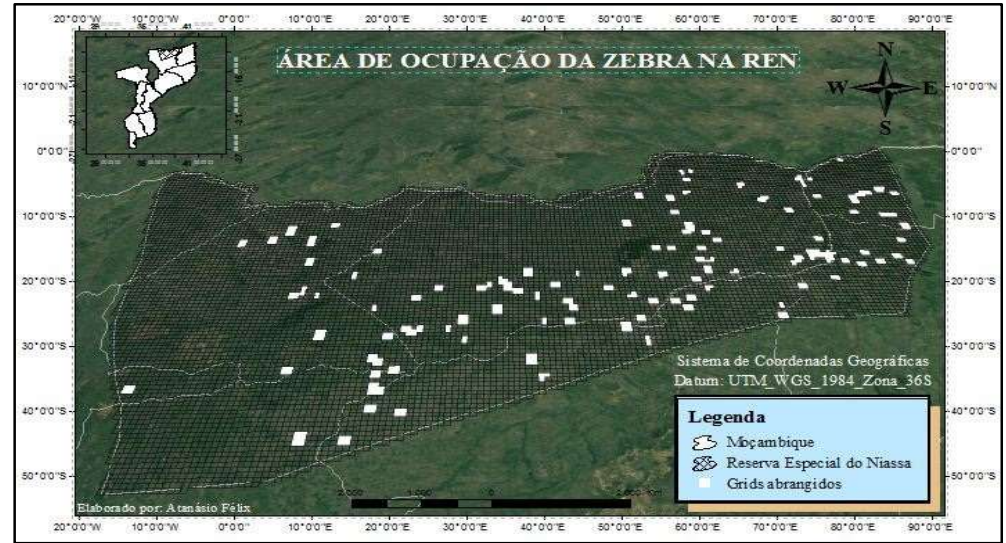

Figura 5: Mapa da AOO da população da Zebra das planícies (Equus quagga crawshayi) na REN no ano de 2017.

\section{DISCUSSÃO}

Os resultados mostram que a Zebra das planícies foi encontrada em 5 das 6 classes de vegetação existentes na REN, a saber: na Floresta Aberta Decídua, nos Dambos, na Vegetação Ribeirinha, na Floresta Sempre Verde e na Floresta Densa Decídua. Os corredores onde a espécie foi encontrada, são permanentes e usados para efetuar a migração de um local para o outro, em busca da sua sobrevivência. A DOW (2017) relata que a Zebra das planícies pode ser sedentária em algumas partes de sua distribuição, mas na maioria dos casos ela passa por movimentos sazonais em resposta à disponibilidade de água. Na Floresta Densa Decídua, a espécie foi encontrada percorrendo corredores junto com as outras espécies, com maior ênfase para Búfalos, Elandes e Pala-Palas. Segundo a EOL (s/d), os grupos populacionais da Zebra das planícies se misturam e migram juntamente com outras espécies que geralmente convivem pacificamente e alertar-seão para predadores. No entanto, as interações agressivas ocasionalmente ocorrem.

A ocorrência da Zebra na REN não é apenas influenciada pelas condições do habitat, mas também influenciada pela ocupação humana. Assim sendo, quanto maior for a ocupação humana de uma determinada área, menor será a probabilidade de ocorrência da população da zebra no local, o que justifica a sua ausência em locais de Floresta com Agricultura Itinerante. Para Harris et al. (2003, citados por PENTER et al., 2008), em ambientes de ocupação humana mamíferos se adaptam de maneiras distintas às alterações antrópicas, sendo que no geral apenas poucas espécies estabelecem populações nesses locais. 
A extensão de ocorrência das zebras na área de estudo está torno de $48,96 \%$ da área total, indicando que os restantes $51,04 \%$ (na qual se trata de maior parte dessa área) não são explorados pela espécie. 0 facto é justificado quando se refere sobre a importância dos mecanismos adotados pelas espécies visando a sua conservação, as espécies, muita das vezes, podem necessitar de condições muito específicas de habitat e quando trechos específicos da floresta não são adequados, estes não são habitados porque correm o risco de desaparecimento. Assim, os agrupamentos irão se formar na natureza a partir da tendência exibida pelos organismos de agregarem-se em função dos locais particulares, na qual as espécies podem se agrupar influenciados pela presença de um ou mais indivíduos, propiciando uma atratividade para vários outros.

A zebra das planícies adota o comportamento definido por este autor de forma a aumentar as suas probabilidades de sobrevivência a quando da sua predação. Este fenómeno pode ser denominado como Princípio de Alee, tal que à medida que o número de indivíduos de uma população aumenta, ou à medida que a densidade populacional aumenta, a sobrevivência e a produção da população também crescem e viceversa.

O valor da área de ocupação da espécie foi baixo em relação ao global da espécie, que para ALA (2015), valores baixos na AOO são sempre esperados porque trata-se da área mais pequena em qualquer estágio de sobrevivência dos existentes. Essa medida reflete o fato de que um grupo de indivíduos de determinado nível taxionómico geralmente não ocorrerá em toda a sua EOO, que pode conter habitats inadequados ou desocupados.

Em concordância com a afirmativa de Hack et al. (2002, citados por MOEHLMAN, 2002), a Zebra das planícies é uma espécie que possui grandes dependências de água, na qual os adultos precisam beber pelo menos uma vez por dia e as fêmeas lactantes podem exigir duas caminhadas diárias para a água, limitando a sua área de proximidade em cinco a dez quilómetros das confiáveis fontes de água. Deste modo, tendo como base a essa citação e na análise da figura 5, nota-se que a população da zebra enfrenta uma fragmentação severa na sua $\mathrm{AOO}$, porque apresenta maior parte dos grupos de indivíduos isolados uns dos outros na sua EOO. O ICMBIO (2013) reitera que neste contexto, o termo fragmentação severa refere-se à população, e não ao habitat, aplicando-se à situação na qual os indivíduos encontram-se em subpopulações pequenas e relativamente isoladas, aumentando o risco de extinção da espécie.

\section{CONCLUSÕES}

Resultados deste estudo permitem concluir que na REN, a Zebra pode ser encontrada na Floresta Aberta Decídua e nos Dambos em busca da vegetação herbácea para a sua alimentação, na Vegetação Ribeirinha e na Floresta Sempre Verde em busca da água nos cursos ou charcos que são permanentes durante todo o ano e na Floresta densa decídua percorrendo corredores junto com as outras espécies, com maior ênfase para Búfalos, Elandes e Pala-Palas.

Além das condições do habitat, a Zebra também é influenciada pela ocupação humana, o que resulta numa EOO de $20.562 \mathrm{~km}^{2}$ obtida pela soma dos 6 MPC's encontrados, e que constitui cerca de 48,96\% da área total, e 0,5\% quando comparado com o valor da EOO da avaliação global da espécie. A população da 
zebra enfrenta uma fragmentação severa na sua $\mathrm{AOO}$, indicando que numa perspectiva de conservação exsitu, a área mínima necessária para a espécie seria de 1.940 km².

\section{REFERÊNCIAS}

ALA. Atlas of Living Australia. Area of Occupancy and Extent of Occurrence. ALA, 2015.

ANAC. Administração Nacional das Áreas de Conservação. Breve informação sobre a Reserva Especial do Niassa (REN). ANAC, 2015.

BONI, V.; QUARESMA, S. J.. Aprendendo a entrevistar: como fazer entrevistas em Ciências Sociais. Revista Eletrônica dos Pós-Graduandos em Sociologia Política da UFSC, v.2, p.6880, 2005.

CANGELA, A. C. N. P.. Caracterização e mapeamento do regime de queimadas na Reserva Especial de Niassa. Maputo: UEM, 2014.

CUNHA, F. P.. Monitoramento de mamíferos terrestres de médio e grande porte. Atibaia, 2013.

DOW. Defenders of Wildlife. Basic Facts About Zebras. DOW, 2017.

EOL. Encyclopedia of Life. Equus quagga (Plains Zebra). $(\mathrm{S} / \mathrm{d})$.

EVERATT, K.. Improving the conservation prospects for lions in the Greater Limpopo Lion Conservation Unit; determining key threats and identifying appropriate solutions. Centre for African Conservation Ecology. Department of Zoology Nelson Mandela Metropolitan University, 2015.

ICMBIO. Instituto Chico Mendes de Conservação da Biodiversidade. Aplicação de Critérios e Categorias da UICN na Avaliação da Fauna Brasileira. Versão 2.0. Brasília: ICMBIO, 2013.

KING, S. R. B.; MOEHLMAN, P. D.. Equus quagga. The IUCN Red List of Threatened Species:e.T41013A45172424. 2016. DOI:
http://dx.doi.org/10.2305/IUCN.UK.20162.RLTS.T41013A451 72424.en

MINAM. Ministério Del Ambiente. Guía de inventário de la fauna silvestre. Dirección General de Evaluación, Valoración y Financiamiento del Patrimonio Natural. MINAM, 2015.

MOAT, J.. Conservation assessment tools: extension for ArcView 3.x, version 1.2. GIS Unit, Royal Botanic Gardens, Kew. 2007.

MOEHLMAN, P. D.. Equids: Zebras, Asses and Horses. Status Survey and Conservation Action Plan. IUCN/SSC Equid Specialist Group. Gland: IUCN, 2002.

PENTER, C.; FABIÁN, M. E.; HARTZ, S. M.. Inventário Rápido da Fauna de Mamíferos do Morro Santana, Porto Alegre, RS. Revista Brasileira de Biociências, Porto Alegre, v.6, n.1, p.9, 2008.

PERES, M. B.; VERCILLO, U. E.; DIAS, B. F. S.. Avaliação do Estado de Conservação das Tartarugas Marinhas. Instituto Chico Mendes de Conservação da Biodiversidade, v.1, n.1, p.45-48, 2011.

PCN. Projeto Carnívoros do Niassa. Dados não publicados. Reserva Especial do Niassa (REN). Bloco L5 Sul. PCN, 2017.

ROVERO, F.; ZIMMERMANN, F.; BERZI, D.; MEEK, P.. “Which camera trap type and how many do I need?" A review of camera features and study designs for a range of wildlife research applications. Hystrix, the Italian Journal of Mammalogy, v.24, n.2, p.148-156, 2013. DOI: https://doi.org/10.4404/hystrix-24.2-8789

SELEMANE, A.; MUIANGA, J.. Reserva de Maputo recebe 225 animais bravios. 2015.

SRN. Sociedade para a Gestão e Desenvolvimento da Reserva Especial do Niassa. Sumário executivo do Plano de Maneio da Reserva Especial do Niassa. (S/d).

A CBPC - Companhia Brasileira de Produção Científica (CNPJ: 11.221.422/0001-03) detém os direitos materiais desta publicação. Os direitos referem-se à publicação do trabalho em qualquer parte do mundo, incluindo os direitos às renovações, expansões e disseminações da contribuição, bem como outros direitos subsidiários. Todos os trabalhos publicados eletronicamente poderão posteriormente ser publicados em coletâneas impressas sob coordenação da Sustenere Publishing, da Companhia Brasileira de Produção Científica e seus parceiros autorizados. Os (as) autores (as) preservam os direitos autorais, mas não têm permissão para a publicação da contribuição em outro meio, impresso ou digital, em português ou em tradução. 